\title{
Comparative analysis between identified injuries of victims of fall from height and other mechanisms of closed trauma
}

\section{Análise comparativa dos fatores preditivos de morte em vítimas de trauma fechado com fraturas pélvicas}

\author{
José Gustavo Parreira'; lucas R. Kanamorli; Guilherme C. J. Valinoto²; Jacqueline A. Giannini Perlingeiro'; Silvia Cristine Solda';
} José CesAr Asser ${ }^{3}$

\section{A}

\begin{abstract}
Objective: to identify predictors of death in blunt trauma patients sustaining pelvic fractures and, posteriorly, compare them to a previously reported series from the same center. Method: Retrospective analysis of trauma registry data, including blunt trauma patients older than 14 y.o. sustaining pelvic fractures admitted from 2008 to 2010. Patients were assigned into group 1 (dead) or 2 (survivors). We used Student's t, qui square and Fisher's tests for statistical analysis, considering $p<0.05$ as significant. Posteriorly, we compared predictors of death between both periods. Results: Seventy-nine cases were included. Mean RTS, ISS and TRISS were, respectively, $6.44+2.22,28.0+15.2$ e $0.74+0.33$. Nineteen patients died $(24,0 \%)$. Main cause of death was hemorrhage $(42,1 \%)$. Group 1 was characterized by $(p<0.05)$ lower systolic blood pressure and Glasgow coma scale means on admission, higher heart rate, head AIS, extremity AIS and ISS means, as well as, higher frequency of severe head injuries and complex pelvic fractures. Comparing both periods, we notice that the anatomic and physiologic severity of injury increased (RTS and ISS means). Furthermore, there was a decrease in the impact of associated thoracic and abdominal injuries on the prognosis and an association of lethality with the presence of complex pelvic fractures. Conclusion: There were significant changes in the predictors of death between these two periods. The impact of thoracic and abdominal associated injures decreased while the importance of severe retroperitoneal hemorrhage increased. There was also an increase in trauma severity, which accounted for high lethality.
\end{abstract}

Key words: Hip fractures. Fractures, closed. Pelvic bones. Prognosis. Trauma severity índices.

\section{INTRODUCTION}

Petic Ivic fractures occur in about $2 \%$ of blunt traumas, with an incidence of 23/100,000 inhabitants in large cities, and mortality between $4 \%$ and $23 \%{ }^{1,2}$. Most fractures of the pelvis are stable and do not result in massive retroperitoneal hemorrhage; only $10 \%$ can be classified as "complex", characterized by instability and severe retroperitoneal bleeding ${ }^{2}$.

The energy required to break the pelvic ring is also responsible for injury to other organs. About $90 \%$ of trauma patients with pelvic fractures have associated injuries, mainly located in the limbs and in the cephalic region ${ }^{3}$. Abdominal injuries may be present in up to $40 \%$ of cases ${ }^{1,4,5}$. In the presence of severe injuries in other body segments, such as head and abdomen, mortality can reach $50 \%{ }^{6}$. For this reason, the mere presence of a fracture of the pelvis indicates severe trauma, with a greater chance of progressing to complications and death ${ }^{1}$.
Several studies found that the prognosis of traumatized with pelvic fractures is mainly related to the severity of associated injuries, and not to the complexity of the fracture itself ${ }^{1,7-10}$. Demetriades et al. ${ }^{8}$ reported in 2002 that of 16,630 trauma patients with pelvic fracture, only $0.8 \%$ died from complications directly related to the fracture. Other studies have also found that the majority of deaths in patients with pelvic fractures was not directly related to them, but to associated injuries 4,5

In general, the literature does not correlate the complexity of pelvic fracture and its mechanical stability with worse prognosis ${ }^{9}$. However, despite being a rare condition, severe retroperitoneal hemorrhage $(\mathrm{SRH})$ is potentially lethal. Miller et al. ${ }^{6}$ observed in 2003 that of 1,171 traumatized patients admitted with pelvic fractures, only $35(0.3 \%)$ had hypotension due to retroperitoneal bleeding. However, in these cases the mortality reached $54 \%$. It is believed that retroperitoneal bleeding may cause $7-33 \%$ of deaths when present in patients with pelvic fractures 7,11 .

1. Emergency Service, Irmandade da Santa Casa de Misericórdia de São Paulo, Department of Surgery, Faculty of Medical Sciences, Santa Casa de Misericórdia de São Paulo; 2. Faculty of Medical Sciences, Santa Casa de Misericórdia de São Paulo. 
In our service, we noticed an increase in the lethality of the blunt trauma with pelvic fractures in recent years ${ }^{1}$. Our hypothesis is that this is related primarily to an increase in the anatomical and physiological severity of trauma, with an increasing role of severe retroperitoneal hemorrhage as main cause. The aim of this study was to analyze the predictors of death in victims of blunt trauma with pelvic fractures.

\section{METHODS}

This study was approved by the Ethics in Research Committee of the Irmandade da Santa Casa de Misericórdia de São Paulo (Opinion 294,227, of 06.13.2013).

At the Emergency Department of the Irmandade da Santa Casa de Misericórdia de São Paulo (ISCMSP), we prospectively collected data of all admitted trauma patients in the emergency room from 2008 to 2010, in order to form a trauma registry for the service quality control. Data were originally collected by surgical residents on patient admission and, subsequently, by the service assisting physicians during hospital stay until discharge. The information was stored in a database.

We conducted a retrospective analysis of the information contained in this trauma registry, including data from blunt trauma victims over the age of 13 years and closed fractures of the pelvis, admitted between 2008 and 2009. Patients with isolated acetabular fractures were not included. Records where the information were not accurate were excluded.

We collected information about the mechanism of injury, admission vital signs, complementary exams, lesions diagnosed, as well as their severity and treatment. For analysis, we considered all variables noted in over $90 \%$ of the protocols. For analysis of the causes of deaths, we considered as "major cause" the one directly determining death. Even if other potential causes were present, we did not consider them the "major cause" if they were not directly linked to death. When more than one "major cause" was identified, we considered as being an "association of factors".

Severity stratification was performed with the following trauma indices: Glasgow Coma Scale (GCS) ${ }^{12}$, Revised Trauma Score (RTS) ${ }^{13}$, Abbreviated Injury Scale (AIS) ${ }^{14}$, Injury Severity Score (ISS) ${ }^{15}$ and TRISS ${ }^{16}$.

The GCS stratifies the level of consciousness of the traumatized using parameters of eye opening, verbal response and motor response, ranging from 3 to 15 . The RTS is a physiological index that uses systolic blood pressure, respiratory rate and Glasgow coma scale, ranging from 0 to 7.8408. The AIS is an organic injury severity scale published by the Association for the Advancement of Automotive Medicine - AAAM. Each organ has lesions grouped in increasing severity, ranging from 1 to 6 . AIS $=1$ injuries are defined as "minor", the AIS $=2$, "moderate",
AIS $=3$, "severe" , AIS $=4$, "very severe", AIS $=5$, "critical" and AIS $=6$, lethal. The ISS is an anatomical index based on the AIS organic injury scale. The lesions are grouped into six segments: head and neck; face; chest; abdomen; extremities and bony pelvis; and external. The most serious injuries of the three most severely affected segments are selected, the sum of their squares being the ISS score. The TRISS is an index that allows the calculation of the probability of survival based on the variables mechanism of injury, age, RTS and ISS.

In this study, we considered as "serious" injuries with AIS e" 3 in the different body segments. We used the classification of Key and Conwell modified by Kane (KCK) to stratify the severity of fractures of pelvis ${ }^{17}$. In this classification, type I fractures are those that do not compromise the pelvic ring; type II fractures compromise the pelvic ring in one point; and the type III affect it in more than one point. We considered as complex the type-III pelvic fractures. Fractures of the pelvis were also classified according to Tile into types $A$ (stable, minimally deviated), B (rotationally unstable but vertically stable) and C (rotationally and vertically unstable) ${ }^{18}$.

In the Emergency Department of Santa Casa de Misericórdia de São Paulo, the treatment protocol for victims of trauma with pelvic fractures involves a multidisciplinary care even in the early stages, including performing FAST (Focused Assessment Sonography for Trauma), chest and pelvis radiography, as well as arterial blood gases analysis in the admission room. In the presence of hemorrhagic shock and pelvic instability, the protocol of resuscitation is triggered, with packed red blood cells, fresh frozen plasma (FFP) and platelets in the ratio $1: 1: 1$, immobilization of the pelvis with sheets is held in conjunction with the orthopedic surgeons in the admission room and, if there is no other hemorrhagic focus in need of operative treatment, selective angiography of the iliac vessels and their branches is indicated. In the presence of other foci of concomitant bleeding, the patient is sent to the operating room for hemostasis, the pelvic bleeding being controlled with external fixation of the pelvis (in the case of orthopedic indication) and / or preperitoneal tamponade with surgical packs.

Victims of closed trauma with pelvic fractures were separated into two groups: Group 1: Death within 30 days of trauma; and Group 2: Survivors.

Variables were compared between the two groups to identify predictors of death. We used the chisquare test for evaluation of qualitative variables. For the analysis of numerical variables, we used the Student's t, and the Fisher's exact test, when necessary. We considered $p<0.05$ as significant.

\section{RESULTS}

Seventy-nine patients were included, $69.6 \%$ males, aged between 14 and 87 years (mean $41.0 \pm 18.9$ 
years). The most common mechanisms of injury was trampling in 36 cases (45.6\%), falls from height in 24 (30.4\%), accidents involving motorcyclists in 15 (19.0\%) car accidents in 4 (5.1\%). The mean systolic blood pressure (PAS) and GCS on admission were respectively $110.0 \pm$ $46.5 \mathrm{mmHg}$ and $12.3 \pm 4.2$. The mean RTS, ISS and TRISS were $6.44 \pm 2.22, ; 28.0 \pm 15.2$ and $0.74 \pm 0.33$, respectively.

Severe injuries were present in head, chest, abdominal and extremity segments in respectively 25 (31.6\%), $24(30.4 \%), 27(34.2 \%)$ and 71 cases (89.9\%). Two craniotomies, one thoracotomy and 19 laparotomies were performed, ten of which non-therapeutic.

Pelvic fractures were classified as types A, B and C (Tile) in 45, (61.6\%) 15 (20.5\%) and 13 (17.8\%) patients, respectively. Six cases could not be classified. According to the classification of KCK, fractures were Types I, II and III in 35, (43.5\%) 18 (23.4\%) and 20 (26.0\%) individuals, respectively. Six cases could not be classified. Of the 79 patients, 7 (8.9\%) underwent angiography / embolization within the first six hours of admission, 18 underwent early external fixation in the operating room, and four were submitted to preperitoneal packing.

Nineteen patients died (24\%). The more frequent causes were hemorrhagic shock in eight cases $(42.1 \%)$, head trauma in $6(31.6 \%)$, infection in $3(15.8 \%)$, pulmonary embolism in 1 (10.4\%) and cardiac arrhythmia in 1 (10.4\%). Of the patients who died, $68.4 \%$ had severe lesions in the cephalic segment, $31.6 \%$ in the thorax, $35 \%$ in the abdomen and $100 \%$ in the extremities. The KCK III fractures were identified in $61.1 \%$, and Tile C, in $50 \%$.

In the comparison of numerical variables between groups 1 and 2, we noted a statistically significant difference in mean SBP at admission ( $p<0.001)$, heart rate at admission $(p=0.024)$, GCS $(p=0.006)$, RTS $(p=0.004)$, AIS head segment $(p<0.001)$, AIS extremities $(p<0.001)$, ISS ( $p<0.001)$, TRISS ( $p<0.001$ ), volume of intravenous crystalloid on admission ( $p=0.003)$ and volume of RBC infused at admission ( $p=0.006$ ) (Table 1).

In the comparison of qualitative variables between groups 1 and 2, it was noted that patients who died had a higher frequency $(p<0.05)$ of serious injury in head segment of Tile C fractures, fractures of KCK III, surgical phlebotomy the inlet area, orotracheal intubation in the admission area, fixation of the pelvic inlet area, nontreatment laparotomy and associated diseases (Table 2). Patients with pelvic fractures Tile C KCK and III had higher lethality to the others (Table 3).

As for the comparison between the two periods, we observed that the most recent sample displayed a significantly higher mean age ( $p=0.012)$, lower mean RTS $(p=0.008)$, higher mean chest AIS $(p=0.031)$, AIS extremities $(p<0.001)$, ISS $(p<0.001)$ and lower average TRISS (Table 4).

In the study published in 2000, the factors predicting mortality were age, as well as injuries with AIS $>2$ in the head, chest and abdomen. When comparing with this series, we noted that only injuries with AIS $>2$ in the head persisted with significant association with mortality. Whereas in the first study we did not find study we observed an association between the complexity of the fracture and mortality, in this period it was clear (Table 5).

\section{DISCUSSION}

The lethality of the victims of pelvic fractures decreased significantly in recent decades, mainly due to

Table 1 - Comparison of mean \pm standard deviation of the numeric variables between groups 1 (deaths) and 2 (survivors) .

\begin{tabular}{|c|c|c|c|}
\hline Variable & $\begin{array}{c}\text { Group } 1 \\
\text { (Deaths) } n=18\end{array}$ & $\begin{aligned} \text { Group } & 2 \\
\text { (Survivors) } & n=61\end{aligned}$ & $p$ \\
\hline Age & $46.2+25.6$ anos & $39.4+16.2$ anos & 0.316 \\
\hline Systolic blood pressure at admission & $66.3+54.6 \mathrm{mmHg}$ & $124.0+33.7 \mathrm{mmHg}$ & $<0.001$ \\
\hline Heart rate at admission & $109.9+26.3 \mathrm{bpm}$ & $94.2+18.2 \mathrm{bpm}$ & 0.024 \\
\hline Respiratory rate at admission & $16.3+12.3 \mathrm{ipm}$ & $18.9+8.6 \mathrm{ipm}$ & 0.420 \\
\hline Glasgow coma scale & $9.6+$ & $13.2+$ & 0.006 \\
\hline Revised trauma score & $4.70+$ & $7.01+1.64$ & 0.004 \\
\hline AIS head & $2.9+$ & $0.9+$ & 0.001 \\
\hline AIS thorax & $1.3+$ & $1.0+$ & 0.497 \\
\hline AIS abdomen & $1.2+$ & $1.4+$ & 0.556 \\
\hline AIS extremities / bone pelvis & $4.6+$ & $3.2+$ & $<0.001$ \\
\hline Injury Severity Score & $40.9+11.4$ & $23.7+13.9$ & $<0.001$ \\
\hline TRISS & $0.43+0.36$ & $0.84+0.25$ & $<0.001$ \\
\hline Volume crystalloids at admission & $4428.5+2234.8 \mathrm{ml}$ & $2425.0+1398.0 \mathrm{ml}$ & 0.003 \\
\hline Volume packed red blood cells at admission & $552.6+665.3 \mathrm{ml}$ & $70.0+249.2 \mathrm{ml}$ & 0.006 \\
\hline
\end{tabular}

AIS: Abbreviated Injury Scale 
Table 2 - Comparison of the frequencies of qualitative variables between groups 1 (deaths) and 2 (survivors).

\begin{tabular}{lccr}
\hline Variable & $\begin{array}{c}\text { Group 1 } \\
\text { (Deaths) }\end{array}=\mathbf{n}$ & $\begin{array}{c}\text { Group 2 } \\
\text { (Survivors) }\end{array}$ & $\mathrm{n=61}$ \\
\hline Severe injuries in head segment & $68.4 \%$ & $20.0 \%$ & $<0.001$ \\
Severe lesions in the thoracic segment & $31.6 \%$ & $30.0 \%$ & 0.896 \\
Severe lesions in the abdominal segment & $35.0 \%$ & $31.6 \%$ & 0.784 \\
Severe injuries in extremities & $100.0 \%$ & $86.7 \%$ & 0.098 \\
KCK type III fractures & $61.1 \%$ & $15.3 \%$ & 0.004 \\
Tile C fractures & $50.0 \%$ & $7.3 \%$ & $<0.001$ \\
Male gender & $63.2 \%$ & $71.7 \%$ & 0.482 \\
Associated comorbidities & $31.6 \%$ & $1.7 \%$ & $<0.001$ \\
Orotracheal intubation at admission & $73.7 \%$ & $21.7 \%$ & $<0.001$ \\
Thorax drainage at admission & $15.8 \%$ & $13.3 \%$ & 0.788 \\
Vain dissection at admission & $42.1 \%$ & $5.0 \%$ & $<0.001$ \\
Pelvic fixation in OR & $42.1 \%$ & $16.7 \%$ & 0.021 \\
Angiography and embolization & $21.1 \%$ & $5.1 \%$ & 0.056 \\
Laparotomy & $42.1 \%$ & $18.3 \%$ & 0.039 \\
Non-therapeutic laparotomy & $36.8 \%$ & $5.0 \%$ & $<0.001$ \\
Open fracture of upper limb & $21.1 \%$ & $6.7 \%$ & 0.070 \\
Open fracture of lower limb & $21.1 \%$ & $6.7 \%$ & 0.070 \\
\hline
\end{tabular}

KCK: Key and Conwell classification modified by Kane.

Table 3 - Mortality of the type of fractures according to the classifications of Key and Conwell modified by Kane (KCK), and of Tile.

\begin{tabular}{|c|c|c|c|}
\hline Type of fracture & Total number & Total deaths & Mortality \\
\hline KCKI & 35 & 5 & $14.7 \%$ \\
\hline KCK II & 18 & 2 & $11.1 \%$ \\
\hline KCK III & 20 & 11 & $55.0 \%$ \\
\hline Tile A & 45 & 6 & $13.3 \%$ \\
\hline Tile B & 15 & 3 & $20.0 \%$ \\
\hline Tile C & 13 & 9 & $69.2 \%$ \\
\hline
\end{tabular}

prioritizing of the control of retroperitoneal bleeding through techniques such as early external fracture fixation, angiography / selective embolization of the internal iliac artery and its main branches and, more recently, the extraperitoneal pelvic packing ${ }^{19,20}$. Concomitant lesions, mainly cranioencephalic, have become the leading causes of death in these patients ${ }^{5,8-10}$. However, in large series that analyze factors related to mortality, there are still cases of death by severe retroperitoneal hemorrhage ${ }^{20}$. It is important to note that when SRH is present, there is an associated high mortality rate.

The mortality observed in our study (24\%) was higher than in previous series 13,5 . This occurred even with the installation of established protocols for treating hemodynamically unstable pelvic trauma victims over the years, as already described. The calculated trauma indices indicated that this increase was directly related to greater physiologic and anatomic severity of victims recently admitted. The mean RTS, ISS, and TRISS of the group of patients who died were respectively $4.70,40.9$ and 0.43 . This represents a group of extremely severe patients, with a probability of survival lower than $50 \%$. The presence of serious injuries in the head segment was significant, reaching $68.4 \%$. However, some control procedure for retroperitoneal bleeding was necessary in most cases. The presence of complex fractures of the pelvis, especially Tile type $C$ and KCK type III, was a factor significantly related to increased mortality. Therefore, retroperitoneal hemorrhage had some role in this scenario.

When comparing with the previously published series of our Service ${ }^{5}$, we clearly observed a worsening in severity of trauma patients with pelvic fractures based on trauma indexes. This may correspond to an improvement in the pre-hospital care system, bringing patients who previously would die before reaching the hospital. We also noted that, contrary to that observed 15 years before, the severity of associated injuries in the chest and abdomen had no significant impact on mortality. Only serious injury 
Table 4 - Comparison of the variables between the two study periods. Numerical variables are presented as mean \pm standard deviation; categorical variables, as frequency in the sample.

\begin{tabular}{|c|c|c|c|c|c|}
\hline \multirow{2}{*}{$\begin{array}{l}\text { Variable } \\
\text { Mean age }\end{array}$} & \multicolumn{2}{|c|}{$\begin{array}{c}1993-1997 \\
n=103\end{array}$} & \multicolumn{2}{|c|}{$\begin{array}{c}2008-2009 \\
n=79\end{array}$} & \multirow{2}{*}{$\begin{array}{c}p \\
0.012\end{array}$} \\
\hline & 34.0 & +18 anos & 41.0 & +18.9 anos & \\
\hline RTS & 7.1 & +1.3 & 6.4 & +2.2 & 0.008 \\
\hline AIS head segment & 1.05 & $+\quad 1.6$ & 1.4 & +1.8 & 0.168 \\
\hline AIS thoracic segment & 0.65 & $+\quad 1.2$ & 1.1 & +1.6 & 0.031 \\
\hline AIS abdominal segment & 1.2 & +1.6 & 1.4 & +1.7 & 0.417 \\
\hline AIS extremities & 2.9 & +1.1 & 3.6 & +1.3 & $<0.001$ \\
\hline ISS & 20.0 & +13.0 & 28.0 & +15.2 & $<0.001$ \\
\hline TRISS & 0.89 & $+\quad 0.2$ & 0.74 & +0.33 & $<0.001$ \\
\hline Fractures KCK III & \multicolumn{2}{|c|}{$32.0 \%$} & \multicolumn{2}{|c|}{$27.4 \%$} & 0.258 \\
\hline Mortality & \multicolumn{2}{|c|}{$19.0 \%$} & \multicolumn{2}{|c|}{$24.7 \%$} & 0.567 \\
\hline
\end{tabular}

RTS: Revised Trauma Score. AIS: Injury Severity Scale. ISS: Injury Severity Score, TRISS: probability of survival, KCK III: fractures type III of Kay e Conwell modified by Kane.

Table 5 - Comparison of factors associated with mortality between the two periods.

\begin{tabular}{lcc}
\hline Variable & $1993-1997$ & $2008-2009$ \\
\hline Age & $p=0.02$ & n.s. \\
AIS $>3$ head & $p=0.002$ & $<0.001$ \\
AIS $>3$ thorax & $p=0.006$ & n.s \\
AIS $>3$ abdomen & $p=0.005$ & n.s \\
Complex pelvic fracture (KCK III) & n.s. & $P=0.004$ \\
\hline
\end{tabular}

AIS: Injury Severity Scale. KCK III: fractures type III of Kay e Conwell modified by Kane.

in the head segment persisted as an important prognostic factor. However, conversely to what was observed previously, the presence of a complex fracture of the pelvis was associated with increased mortality.

Palmcrantz et al. ${ }^{20}$ reported high mortality in trauma patients with pelvic fractures, reaching $31 \%$. They observed that the severity of the pelvic fracture was an important prognostic factor and that the lethality was associated with a higher ISS (mean 36 in those who died). These authors found higher mortality in type $C$ fractures and victims of falls from heights over six meters. In our study, this was one of the most common mechanisms of trauma (30.4\% of cases).

It is interesting to note that victims of complex fractures of the pelvis usually display multiple lesions, and often the cause of death cannot be solely attributed to one factor only. In our data, we found that most patients who died had serious injuries in other body segments, or even serious orthopedic injuries that required surgical hemostasis in the operating room, such as open fractures of upper and lower limbs. That is, the hemorrhagic sites are often multiple. In 2008 Hauschild et al. ${ }^{21}$ reported greater lethality specifically in trauma victims with pelvic fractures that required some "emergency procedure". In our study, we observed higher mortality in those requiring intubation and phlebotomy at admission, chest drainage, external fixation of pelvic fracture, angiography / embolization and laparotomy.

These data support the idea that success in prognosis lies on the rapid control of hemorrhagic foci ${ }^{22-24}$. Often, this is only possible in the operating room, given the frequency of associated injuries. In the services that have the possibility to perform angiography and embolization in the operating room, this should be considered early. If there is no such possibility, the preperitoneal pelvic packing is an increasingly held option ${ }^{22}$. Some authors advocate adding the ligation of internal iliac arteries through the preperitoneal access as a "rescue measure" ${ }^{23}$. This information reinforces the need to resuscitate these critically ill patients from the start in a room with resources to perform various diagnostic and therapeutic procedures together.

The role of early external fixation of the pelvic fracture is still under review. While some authors reported a lower mortality rate and better prognosis in patients undergoing this type of treatment, others prefer to control retroperitoneal bleeding primarily by angiography and embolization. Currently, it is known that the indication of the latter is selective. The protocols vary among institutions and even among societies ${ }^{23-26}$. It is known that while early external fixation is able to control venous bleeding, 
angiography / embolization would be the option for those with arterial bleeding. While most patients with retroperitoneal bleeding in association with pelvic fractures have complex venous bleeding, it is known that mortality is higher in when there is arterial bleeding. In our study, the procedure most often performed to control retroperitoneal bleeding was external fixation. In the patients who died, about 20\% underwent angiography / embolization as the first procedure to control retroperitoneal hemorrhage, and $42 \%$ underwent early external fixation.

This study demonstrated that the treatment of victims of trauma with pelvic fractures remains a challenge. This scenario entails great energy dissipation, lesions in multiple organs and systems, as well as possible sources of bleeding difficult to control. Mortality remains high, despite more aggressive resuscitation protocols. There is no conduct uniformity of the proposed algorithms, since they require local adaptation. Further studies detailing the exact causes and conditions associated with lethality should be conducted with the aim to expose the critical points that hinder the application of the suggested protocols. The severity of these patients will likely continue to increase and there is need for specific preparation. Only with the training of a multidisciplinary group of fast action and with locally well established protocols, there will be a chance to diminish mortality in victims of complex fractures of the pelvis. Probably the answer to the most critical cases will be the development of multi-functional emergency rooms, enabling both rapid diagnosis by computed tomography and prompt treatment, whether by open surgery or by interventional radiology.

In conclusion, there was a significant difference between the two study periods, represented by an increase in the severity of the sample and greater impact of retroperitoneal hemorrhage as a cause of death in the latest period.

\title{
R E S U M O
}

\begin{abstract}
Objetivo: analisar os fatores preditivos de morte nas vítimas de trauma fechado com fraturas pélvicas. Métodos: análise retrospectiva dos dados de registro de trauma, incluindo as vítimas trauma fechado com fraturas de pelve e idade superior a 14 anos. Os que faleceram formaram o grupo 1 e, os sobreviventes, o grupo 2. Utilizamos os testes $t$ de Student, Fisher e Qui-quadrado para a análise estatística, considerando $p<0,05$ como significativo. Posteriormente comparamos os fatores preditivos de morte entre os períodos estudados. Resultados: Foram incluídos 79 doentes. As médias do RTS, ISS e TRISS foram, respectivamente, 6,44 + 2,22; $28,0+15,2$ e 0,74 + 0,33. Houve 19 óbitos (24\%). A causa principal foi o choque hemorrágico (42,1\%). Os que morreram apresentaram, significativamente $(p<0,05)$, menor média de pressão arterial sistólica e escala de Glasgow à admissão, maior média de frequência cardíaca à admissão, AIS segmento cefálico, AIS em extremidades e ISS, como também, maior frequência de lesões graves em segmento cefálico e de fraturas complexas de pelve. O período mais recente se caracterizou por maior gravidade anatômica e fisiológica da amostra, como também, diminuição do impacto das lesões associadas (tórax e abdome) sobre a letalidade. Ao contrário do observado anteriormente, houve relação significativa entre a complexidade da fratura de pelve e letalidade. Conclusão: Houve diferença significativa entre os dois períodos, representada por aumento na gravidade da amostra e maior impacto da hemorragia retroperitoneal como causa de morte.
\end{abstract}

Descritores: Fraturas do quadril. Fraturas fechadas. Ossos pélvicos. Prognóstico. Índices de gravidade do trauma.

\section{REFERENCES}

1. Cordts Filho RM, Parreira JG, Perlingeiro JAG, Soldá SC, Campos T, Assef JC. Fratura de pelve: um marcador de gravidade em trauma. Rev Col Bras Cir. 2011;38(5):310-6.

2. Gänsslen A, Giannoudis P, Pape HC. Hemorrhage in pelvic fracture: who needs angiography? Curr Opin Crit Care. 2003;9(6):515-23.

3. Parreira JG, Haddad L, Rasslan S. Lesões abdominais nos traumatizados com fraturas de bacia. Rev Col Bras Cir. 2002;29(3):153-60

4. Dalal SA, Burgess AR, Siegel JH, Young JW, Brumback RJ, Poka A, et al. Pelvic fracture in multiple trauma: classification by mechanism is key to pattern of organ Injury, resuscitative requirements, and outcome. J Trauma. 1989;29(7):981-1000; discussion 1000-2.

5. Gustavo Parreira J, Coimbra R, Rasslan S, Oliveira A, Fregoneze M, Mercadante $M$. The role of associated injuries on outcome of blunt trauma patients sustaining pelvic fractures. Injury. 2000;31(9):677-82

6. Miller PR, Moore PS, Mansell E, Meredith JW, Chang MC. External fixation or arteriogram in bleeding pelvic fracture: initial therapy guided by markers of arterial hemorrhage. J Trauma. 2003;54(3):437-43.
7. Chien L-C, Cheng H-M, Chen W-C, Tsai M-C. Pelvic fracture and risk factors for mortality: a population-based study in Taiwan. Eur J Trauma Emerg Surg. 2010;36(2):131-7.

8. Demetriades D, Karaiskakis M, Toutouzas K, Alo K, Velmahos G, Chan L. Pelvic fractures: epidemiology and predictors of associated abdominal Injuries and outcomes. J Am Coll Surg. 2002;195(1):110.

9. Lunsjo K, Tadros A, Hauggaard A, Blomgren R, Kopke J, AbuZidan F. Associated injuries and not fracture instability predict mortality in pelvic fractures: a prospective study of 100 patients. J Trauma. 2007;62(3):687-91.

10. Sathy AK, Starr AJ, Smith WR, Elliott A, Agudelo J, Reinert CM, et al. The effect of pelvic fracture on mortality after trauma: an analysis of 63,000 trauma patients. J Bone Joint Surg Am. 2009;91(12):2803-10.

11. Burkhardt $M$, Nienaber $U$, Krause J, Pizanis A, Moersdorf $P$, Culemann $U$, et al. Complex pelvic traumas: Data linkage of the German Pelvic Injury Register and the TraumaRegister DGU®. Unfallchirurg. 2014 Apr 4. [Epub ahead of print].

12. Teasdale G, Jennett B. Assessment of coma and impaired consciousness. A practical scale. Lancet. 1974;2(7872):81-4. 
13. Champion HR, Sacco WJ, Copes WS, Gann DS, Gennarelli TA, Flanagan ME. A revision of the Trauma Score. J Trauma. 1989;29(5):623-9.

14. Association for Advancement of Automotive Medicine (AAAM). The Abbreviated Injury Scale (AIS). A brief introduction. 1990 Revision. Ilinois, USA: AAAM, 1998. Available in: <http:// www.tarn.ac.uk/content/downloads/72/coding.pdf>

15. Baker SP, O'Neill B, Haddon W Jr, Long WB. The injury severity score: a method for describing patients with multiple injuries and evaluating emergency care. J Trauma. 1974;14(3):187-96.

16. Boyd CR, Tolson MA, Copes WS. Evaluating trauma care: the TRISS method. Trauma Score and Injury Severity Score. J Trauma. 1987;27(4):370-8.

17. Kane WJ. Fractures of the pelvis. In: Rochwood CA, Green DP, editors. Fractures in adults. Philadelphia: Lippincott, 1984. p.1093210.

18. Osterhoff G, Scheyerer MJ, Fritz Y, Bouaicha S, Wanner GA, Simmen $\mathrm{HP}$, et al. Comparing the predictive value of the pelvic ring injury classification systems by Tile and by Young and Burgess. Injury. 2014;45(4):742-7.

19. Cheng $M$, Cheung MT, Lee KY, Lee KB, Chan SC, Wu AC, et al Improvement in institutional protocols leads to decreased mortality in patients with haemodynamically unstable pelvic fractures. Emerg Med J. 2013 Dec 10. [Epub ahead of print]

20. Palmcrantz J, Hardcastle TC, Naidoo SR, Muckart DJ, Ahlm K, Eriksson A. Pelvic fractures at a new level 1 trauma centre: who dies from pelvic trauma? The Inkosi Albert Luthuli Central Hospital experience. Orthop Surg. 2012;4(4):216-21.

21. Hauschild O, Strohm PC, Culemann U, Pohlemann T, Suedkamp $N P$, Koestler $W$, et al. Mortality in patients with pelvic fractures: results from the German pelvic injury register. J Trauma. 2008;64(2):449-55

22. Burlew CC, Moore EE, Smith WR, Johnson JL, BiffI WL, Barnett CC, et al. Preperitoneal pelvic packing/external fixation with secondary angioembolization: optimal care for life-threatening hemorrhage from unstable pelvic fractures. J Am Coll Surg. 2011;212(4):62835; discussion 635-7.

23. Eckroth-Bernard K, Davis JW. Management of pelvic fractures. Curr Opin Crit Care. 2010;16(6):582-6

24. Gabbe BJ, de Steiger R, Esser M, Bucknill A, Russ MK, Cameron PA. Predictors of mortality following severe pelvic ring fracture: results of a population-based study. Injury. 2011;42(10):985-91.

25. Cullinane DC, Schiller HJ, Zielinski MD, Bilaniuk JW, Collier BR, Como J, et al. Eastern Association for the Surgery of Trauma practice management guidelines for hemorrhage in pelvic fracture-update and systematic review. J Trauma. 2011;71(6):1850-68.

26. Davis JW, Moore FA, McIntyre RC Jr, Cocanour CS, Moore EE, West MA. Western trauma association critical decisions in trauma: management of pelvic fracture with hemodynamic instability. J Trauma. 2008;65(5):1012-5.

Received on 30/01/2014

Accepted for publication 15/03/2014

Updated 05/2014

Conflict of interest: none.

Source of funding: none.

Mailing address:

José Gustavo Parreira

E-mail: jgparreira@uol.com.br 